\title{
EL MONSTRUO FEMENINO. LO SINIESTRO Y LA CONSTRUCCIÓN DE LO MATERNO EN FURTIVOS
}

\section{The Feminine Monster. The Uncanny and the Construction of Motherness in Furtivos}

\author{
Dra. Silvia GUILLAMÓN CARRASCO \\ Profesora Ayudante Doctora, Universidad de Valencia, España \\ E-mail: silvia.guillamon@uv.es \\ (i) https://orcid.org/0000-0001-7504-0750
}

Fecha de recepción del artículo: 20/09/2018

Fecha de aceptación definitiva: 15/10/2018

\begin{abstract}
RESUMEN
La figura materna encarna una de las metáforas más recurrentes en el cine español del tardofranquismo y la transición. Una metáfora que ha sido interpretada como un recurso de crítica social hacia la dictadura influido, en gran medida, por las connotaciones simbólicas que el franquismo había proyectado sobre la maternidad. Su conexión con el pasado dictatorial, funcionando en la pantalla como una personificación monstruosa y siniestra del aparato represor franquista, hace de lo materno un espacio privilegiado para el despliegue de narrativas fílmicas que exploran las relaciones de poder en el seno familiar como símbolo de la relación entre el sujeto y el Estado. Este artículo aborda la representación de la figura materna en la película Furtivos (José Luis Borau, 1975), analizándola como un síntoma cultural del contexto de transición democrática en que la sociedad española se encontraba inmersa.
\end{abstract}

Palabras clave: maternidad; lo siniestro; cine español; psicoanálisis; feminismo.

\begin{abstract}
The maternal figure embodies one of the most recurrent metaphors in Spanish cinema of late-Francoism and transition, a metaphor that has been read as a device of social criticism towards the dictatorship. Largely due to the symbolic connotations that the Franco regime had projected on motherhood, it has been connected with the dictatorial past, functioning on the screen as a monstrous and uncanny personification of the Francoist repressive apparatus. Thus the maternal has become a privileged space for the deployment of film narratives that explore how power relations within the family can be portrayed as a symbol of the relationship between the subject and the State. This article deals with the representation of the maternal figure in Furtivos (José Luis Borau, 1975), understood as a cultural symptom of the process to-ward the democratic transition in which Spanish society was immersed.
\end{abstract}

Key words: motherhood; the uncanny; Spanish cinema; psychoanalysis; feminism. 


\section{INTRODUCCIÓN ${ }^{1}$}

La figura materna se ha convertido en una de las metáforas más recurrentes en el cine español de mediados y finales de los años setenta. Diversos autores, como Hopewell (1986), Kinder (1993), Evans (1999), Van Liew (2001) o Gámez Fuentes (2003), entre otros, han destacado la importancia de lo materno como un espacio simbólico que puede ser interpretado en relación con los procesos históricos de la transición a la democracia, viendo esta figura como un recurso metonímico de crítica social, influido por las connotaciones simbólicas que el régimen había proyectado sobre la maternidad. Así, Gámez Fuentes (2003) ha subrayado la necesidad de abordar lo materno desde posiciones que lo asuman no tanto como un mero reflejo de las operaciones sociales, sino más bien como un lugar desde el que poder contestar o lidiar con ciertas cuestiones de relevancia histórica, como pueda ser, en este caso, la relación de la sociedad española con el pasado dictatorial.

Este contexto de bisagra entre el tardofranquismo y la inminente transición ha propiciado ciertas configuraciones de lo materno en el cine que, bajo la forma de lo perverso, lo incestuoso o lo furtivo, vehiculan la crítica política al régimen anterior. Este tipo de cine, desarrollado en los años setenta, ha sido calificado por Ballesteros (2001) como un cine «simbólico-familiar», un cine «en el que abundan familias disfuncionales de padres fantasmáticos o monstruosos, madres castradoras inspiradas por la lorquiana Bernarda Alba y niños y niñas en permanente búsqueda de conocimiento filial o en línea de fuga de la casa paterna (...)» y que «refiere alegóricamente al pasado sociopolítico de represión, aislamiento y corrupción» (2001, p. 272).

Debemos tener en cuenta, además, que la tematización de lo materno deviene un espacio privilegiado para el despliegue de narrativas que se han visto influidas por las formulaciones freudianas en torno a la familia. En el contexto que nos compete, han dado lugar a relevantes ficciones cinematográficas en las que se exploran las relaciones de poder en el seno familiar, como metáfora política de la relación entre el individuo y la sociedad, tales como Ana y los lobos (1972), Cría cuervos (1976) o Mamá cumple cien años (1979), de Carlos Saura, Camada negra (1977) de Manuel Gutiérrez Aragón o Furtivos (1975), de José Luis Borau.

Habida cuenta de la importancia de esta problemática en el cine de la transición, este artículo se propone analizar la construcción discursiva de lo materno en Furtivos, uno de los filmes más representativos del período. Estrenada a solo dos meses de la muerte del dictador ${ }^{2}$ y galardonada con la Concha de Oro en el Festival de San Sebastián, la película de Borau fue abrazada inmediatamente por la crítica, tanto nacional como internacional, que vio en la cinta «una suerte de alegoría sobre el franquismo agónico» (Company, 2012, p. 93). Como han señalado diversos autores (Sánchez Vidal, 1990; Heredero, 1993 o Aranzubia, 2012) en el momento de su estreno la crítica cinematográfica apuntó las líneas principales en las que se situarían los debates e interpretaciones en torno al filme, a saber: la problemática adscripción genérica al «drama rural» (Muñoz Álvarez, 2011, p. 66), la relación metafórica con la España de la dictadura3; el sustrato de cuento subyacente a la estructura dramática o la ex-

\footnotetext{
${ }^{1}$ Esta investigación fue realizada en el marco del Proyecto de investigación «Interculturalidad, biopolítica y tecnologías de género», financiado por la Conselleria de Educación, Investigación, Cultura y Deporte de la Generalitat Valenciana (AICO/2017/123).

${ }^{2}$ El filme salió a la luz pública tras un intenso pulso con la censura. En una entrevista reproducida en el libro de Martínez de Mingo (1997), Borau explica cómo consiguió sortear la censura y lograr que la película fuera estrenada en su totalidad (a excepción únicamente de un plano de la fachada del Gobierno Civil de Segovia en el rollo primero). También en el capítulo que Sánchez Vidal (1990) dedica al filme, en su monografía sobre el director, se pueden consultar con detalle los problemas que la película tuvo con la censura.

${ }^{3}$ La trama está situada claramente en los años del tardofranquismo: en una de las primeras secuencias, en las que la acción acontece en un mercadillo, se oye de fondo «Un rayo de sol», interpretada por Los diablos, que fue la canción del verano en (C) Ediciones Universidad de Salamanca / CC BY - NC ND Fonseca, Journal of Communication, n. 17, 2018, pp. 173-191
} 
presión elíptica de la violencia ${ }^{4}$. Como señala Heredero (1993), la crítica y la historiografía anglosajonas se centran principalmente en las lecturas metafóricas y el análisis freudiano del filme. En este contexto de interpretación de Furtivos se ha desarrollado el enfoque psicoanalítico-feminista, una de las principales líneas de investigación de los últimos treinta años que, como señala Aranzubia, «aplica el psicoanálisis y hace un especial hincapié en las cuestiones de género» (2012, p. 149). El presente artículo, enmarcado en esta misma línea, considera la hipótesis de contemplar la noción de «lo siniestro» en el filme como un aspecto fundamental para comprender la construcción de la figura materna como monstruosa. El foco de nuestra atención se centra en «lo siniestro» en tanto se considera un concepto clave en la teoría psicoanalítica, pero también en la reinterpretación que, desde el feminismo, ha propuesto Kristeva (enfocada explícitamente en la reflexión sobre lo materno).

En relación con lo expuesto, los objetivos específicos que nos planteamos son los siguientes: en primer lugar, realizar una revisión teórica del concepto de lo siniestro y su conexión con la construcción cultural de lo materno; en segundo lugar, estudiar la figura materna en el filme y su vínculo con lo siniestro como un elemento sintomático del contexto socio-histórico de la transición y, en tercer lugar, constatar la relevancia de la interdisciplinariedad y la pertinencia del enfoque feminista en el abordaje del análisis fílmico de Furtivos.

\section{APROXIMACIÓN TEÓRICA Y METODOLÓGICA}

Nuestro acercamiento al objeto de estudio parte de una comprensión del cine como una práctica social y cultural de construcción sígnica, como una tecnología de representación implicada en la construcción de los significados sociales y culturales (Heath, 1981). En este sentido, se enmarca en lo que Casetti (2000) ha denominado las «teorías de campo», un paradigma caracterizado por la interdisciplinariedad y la apertura que busca un diálogo entre los diferentes campos del conocimiento, reconociendo paralelamente el saber situado como un aspecto intrínseco a toda actividad investigadora. Como ha señalado Casetti, este tipo de investigación nace «de la existencia de un problema revelador de las preocupaciones del teórico y de los síntomas del objeto teorizado» (2000, p. 201).

Esta postura se deriva de la formulación de los problemas de investigación que este paradigma asume. En tanto se plantea el desafío de identificar, formular y responder a preguntas globales que alcanzan a diversos sectores disciplinares (como aquellas que se interesan por el sujeto, la construcción de la identidad o la representación), este tipo de investigación pone en relación ámbitos aparentemente inconexos, viniendo a cuestionar la autosuficiencia de la que hacen gala las disciplinas.

Un análisis fílmico que pretenda abordar la significación de un cierto imaginario en torno a lo materno, ahondando en la relación entre texto y contexto, deberá partir necesariamente de un acercamiento interdisciplinar al objeto de estudio. Así mismo, deberá contemplar un marco teórico y metodológico adecuado, especializado en el análisis de la representación de lo femenino en el cine y en su significación cultural e histórica.

De acuerdo con lo expuesto, y en consonancia con el carácter interdisciplinar que inspira este estudio, el análisis que presentamos en torno a la figura materna en Furtivos toma en consideración las conexiones teórico-metodológicas entre tres perspectivas ampliamente consolidadas en ámbito de la investigación fílmica: el psicoanálisis, el análisis textual (enmarcado en la semiótica fílmica) y el femi-

1970. En el guion podemos leer: «se oye la canción que estuvo de moda hace un par de veranos» (Borau y Gutiérrez Aragón, 1993, p. 24).

${ }^{4}$ Para una consulta detallada de las críticas cinematográficas publicadas en el momento de su estreno, véase el libro de Rodríguez (2008). 
nismo. La convergencia entre estos tres enfoques presenta una larga tradición en el campo de los estudios de género y en la teoría fílmica feminista (Colaizzi, 2007; Zurián Hernández y Herrero Jiménez, 2014), que ha acudido desde sus inicios tanto a la semiótica como al psicoanálisis para realizar sus análisis, aunque alejándose tanto de las rigideces disciplinarias (que corren el riesgo de caer en un excesivo textualismo) como de los acercamientos centrados exclusivamente en el contenido, que dejan de prestar atención a la retórica y la forma del texto fílmico para simplemente centrarse en los temas de los que se habla. En este sentido, el análisis que hemos realizado en torno a la figura materna en Furtivos aborda la dimensión textual identificando tanto los recursos narrativos (la estructura del relato, la construcción de los personajes y sus relaciones) como los recursos expresivos (los componentes del plano, los tipos de encuadre, la iluminación, el sonido, los movimientos de cámara y la sintaxis fílmica). Si entendemos que el cine es una práctica significante específica que funciona con una serie de códigos (verbales y visuales) que la distinguen claramente de otro tipo de producciones discursivas, no podemos obviar los materiales expresivos con los que trabaja, pues son estos materiales los que van a erigir los diversos modos de representación y de construcción de la imagen.

\section{EL CONCEPTO DE LO SINIESTRO EN EL PSICOANÁLISIS}

El concepto de lo siniestro, ampliamente desarrollado por el discurso psicoanalítico, conecta culturalmente con la idea de feminidad como lugar de la castración: la mujer resulta siniestra porque está castrada, su condición femenina se identifica con la falta y su representación trae a colación el recuerdo reprimido de la amenaza de castración. En Lo siniestro Freud expone este concepto detalladamente. La traducción española de «das Unheimlich» («lo siniestro») no contempla la complejidad semántica de la voz alemana, complejidad que podemos entender a partir de la reflexión de Freud acerca de las distintas acepciones que encuentra en el diccionario y que favorecen su conexión con la noción psicoanalítica del complejo de castración. Es necesario, por este motivo, tener en cuenta esta descripción para atender a las especificidades de la definición en el discurso psicoanalítico. En el texto de Freud, lo siniestro queda definido como «aquella suerte de espantoso que afecta las cosas conocidas y familiares desde tiempo atrás» (1973, p. 219). La voz alemana queda referida a lo inquietante, aquello que provoca un terror atroz y se opone a su antónimo «Heimlich» en la acepción que designa lo familiar, íntimo, amable. Al mismo tiempo, esta última en una segunda acepción excede su propio significado, va más allá de lo íntimo, situándose en lo secreto, lo oculto, lo impenetrable. Este significado llevado más lejos se refiere a lo escondido, lo peligroso. «Heimlich», por tanto, no posee un sentido único, sino que pertenece a dos grupos de representaciones alejadas entre sí: se trata de lo que es familiar, confortable, por un lado; y de lo oculto, disimulado, por el otro. La segunda acepción en «Heimlich» evoluciona hacia la ambivalencia hasta que termina por coincidir con su antítesis, «Umheimlich», que acaba siendo, como indica Freud, una especie de «Heimlich». Yendo un poco más lejos en la noción de lo siniestro, se trata, por tanto, de lo extraño inquietante que se manifiesta cuando debería estar oculto y que nos muestra la otra cara de lo familiar, de lo amable, volviendo estas vivencias siniestras, sorpresivas, inquietantes, sobrecogedoras.

En lo siniestro, ese juego entre lo familiar y lo extraño, por el hecho mismo de que se encuentra concentrado en el mismo objeto, se complica asombrosamente y la paradoja que anuncia Freud es que el terror se produce porque lo que antes nos era familiar emerge bajo un aspecto amenazante. En este sentido, a partir de la alusión al cuento de E. T. A. Hoffmman «El arenero», expone cómo lo reprimido regresa al sujeto en forma espantosa, al tiempo que refiere el miedo a la castración a través del personaje del arenero, que castra arrancando los ojos a los niños que se han portado mal. Lo siniestro vendría expresado por la presencia del arenero (el padre/la ley) que regresa en distintas formas y en 
episodios repetidos a la vida de Nataniel provocando graves crisis de locura en el joven. Lo siniestro es, según Freud, el retorno de lo familiar (el deseo primigenio hacia la madre), que ha sido reprimido y que regresa a nosotros en forma de trauma. En este sentido, esta suerte de espanto es lo que debería haber permanecido oculto y que, sin embargo, se ha manifestado, regresa a través de esta figura, arruinando constantemente la vida amorosa del joven:

\begin{abstract}
¿Por qué el Hombre de la Arena aparece todas las veces como perturbador del amor? Hace que el desdichado estudiante se malquiste con su novia y con el hermano de esta, que es su mejor amigo; aniquila su segundo objeto de amor, la bella muñeca Olimpia, y lo constriñe al suicidio cuando está por consumar una dichosa unión con su Clara, a quien ha recuperado. (Freud, 1973, p. 232).
\end{abstract}

Freud apunta aquí a la idea de la oposición paterna a la realización del deseo primigenio del niño (la madre), suplantado ahora por su novia o la muñeca Olympia. Donde aparece el deseo aparece el arenero, y con él la castración, renovando algo que ha sido olvidado y enterrado en el inconsciente. Como ha señalado González Requena, «tal es, pues, el abordaje freudiano: algo, en el interior del sujeto, en su inconsciente, habría quedado encerrado, reprimido, y al retornar a su conciencia sería vivido como siniestro» (1997, p. 53).

Sin embargo, otro detalle más relaciona la castración con la madre que se coloca, de hecho, como agente fáctico de la amenaza castradora. Esta «madre castradora» estaría relacionada con la «madre fálica» que, parcialmente, recupera en su discurso el franquismo, esa madre vigilante de la moral familiar a la que se refiere Gámez Fuentes en su lectura de la ideología franquista sobre lo materno (2004).

Debemos advertir que el concepto de lo siniestro también está relacionado con esa otra faceta de la madre, la que nos remitiría a lo pre-edípico, a lo que, según el psicoanálisis, conecta con lo primigenio, lo pre-lingüístico, lo que existiría antes de la castración y la Ley. A partir de este aspecto, el concepto de lo siniestro ha dado lugar a la reflexión sobre la maternidad como abyección, como alteridad amenazante en la cultura occidental. Vegetti-Finzi (1996) ha apuntado en esta línea cómo el concepto de lo siniestro en Freud acaba remitiendo, finalmente, a esta noción de la madre: «Lo inquietante sería (...) esa cualidad aterradora que emana de una represión arcaica como el fantasma del cuerpo materno» (1996, p. 131). Esta emanación de lo materno fuera del arco de lo simbólico está presente en Furtivos, como veremos en el análisis.

La concepción de lo siniestro como algo que perturba la identidad, como algo que nos remite a aquello que ha sido reprimido por el sujeto en su acceso a lo simbólico (todas las experiencias preedípicas que nos remiten al vínculo y la relación corporal con la madre), ha sido analizada ampliamente por Kristeva con su noción de lo abyecto. La noción de la abyección es bastante compleja puesto que la autora, a lo largo de la obra, se refiere a múltiples aspectos que pueden provocar este sentimiento de desagrado en el sujeto. Podemos afirmar, no obstante, que lo abyecto estaría referido a todo aquello que perturba una identidad y provocaría en el sujeto un fuerte sentimiento de angustia, repugnancia y rechazo:

No es la falta de limpieza o de salud lo que causa la abyección sino aquello que perturba una identidad, el sistema, el orden, lo que no respeta los bordes, las posiciones, las reglas. Lo que está en medio, lo ambiguo, lo mezclado. (Kristeva, 1989, p. 27). 
Lo abyecto sería la contrapartida de lo simbólico, lo que la norma social quiere ocultar, esconder, prohibir. Lo abyecto nos remite a la disolución de las fronteras de lo materno-filial, a esa fusión preedípica originaria de la que el sujeto necesita zafarse para penetrar en lo social. La emergencia de esa fusión nos produciría el horror, ese sentimiento del que no puede deshacerse el sujeto por completo y que revelaría la imposibilidad de una identidad coherente y unificada. La noción de la abyección es desafiante puesto que, como ha señalado Colaizzi, nos zarandea al contradecir la supuesta coherencia e integridad del cuerpo, es un atentado contra la norma, contra la categoría, contra la identidad del sujeto, contra «el dualismo sobre el que el pensamiento occidental ha basado su visión del mundo» (2006, p. 170).

\section{LA MATERNIDAD Y LO SINIESTRO EN FURTIVOS}

El concepto de lo siniestro parece haber atravesado el tratamiento de la maternidad en Furtivos en dos sentidos concretos, tal como expondremos más adelante: por una parte, la madre deviene monstruosa en su deseo de poseer al hijo, esto es, en su afán por evitar el sepultamiento del complejo edípico. Por otra parte, la figura de la madre aparece en el cine de estos años como una figura ominosa que se encuentra estrechamente relacionada con el fantasma del franquismo. En efecto, podemos observar cómo la figura de la madre, idealizada en el imaginario socio-sexual del régimen, resurge asociada al trauma de la dictadura, esto es, aparece simbólicamente representada como amenaza durante los años de la transición. Como trataremos de mostrar en el análisis, el filme que nos compete aborda la crítica al régimen anterior a partir de la representación de la maternidad en relación con lo siniestro. Un concepto que, en el discurso psicoanalítico, conecta la idea de feminidad con la castración: la Mujer resulta siniestra porque está castrada, su condición femenina se identifica con la falta y su representación trae a colación el recuerdo reprimido de la amenaza de castración.

Comenzaremos nuestro análisis exponiendo las principales líneas de fuerza de la película, contextualizando las relaciones de los personajes y la deriva de la trama para, posteriormente, abordar la específica significación de lo materno en la película.

\subsection{EL DESPERTAR DEL DESEO}

El filme pone en escena la posesiva e incestuosa relación entre Ángel (el personaje principal de la historia) y su madre, Martina. Dedicados a la caza furtiva, viven en la montaña alejados de todo y aislados en un sofocante ambiente rural. En una visita a la capital, Ángel conoce a Milagros, una joven que ha escapado del reformatorio Las Divinas para ver a su novio «El Cuqui», un conocido delincuente que está huyendo de la policía. Ángel la protege en su casa, pero la animadversión de su madre hacia la chica termina con el asesinato de esta a manos de Martina. Ya con Milagros fuera de escena, miente a su hijo explicándole que la chica le ha abandonado y ha huido con su antiguo novio, pero una noche Ángel se percata de la verdad gracias al descubrimiento de un cabás donde Milagros solía guardar sus recuerdos y que estaba escondido encima del armario de la alcoba. A la mañana siguiente, Ángel conduce a su madre a la Iglesia, donde se está llevando a cabo el funeral de Milagros, y la obliga a confesarse antes de proceder a su ejecución en el bosque. En la última secuencia, vemos cómo Ángel entra en casa, entorna los postigos de la ventana, dejando la estancia en penumbra. Seguidamente saca el cabás de su escondrijo, buscando entre los recuerdos de la chica la fotografía de la niña Milagros, imagen que cierra el filme.

Una vez expuesta la trama del filme, analizaremos en este apartado las primeras secuencias de la película, en las que se sitúa a los personajes principales y se expone su relación en función de un marco socio-histórico signado por la violencia y la represión. Analizaremos el encuentro entre Milagros y

(C) Ediciones Universidad de Salamanca / CC BY - NC ND Fonseca, Journal of Communication, n. 17, 2018, pp. 173-191 
Ángel, con el consecuente despertar del deseo del protagonista y la inminente ruptura de la relación edípica con la madre, así como la representación del personaje de Milagros y su inclusión en el relato como motor narrativo en el proceso de separación madre-hijo.

La violencia que atraviesa el filme aparece simbolizada en la primera imagen de la película, que muestra un primer plano de una caja de balas (Figura 1). Como ha indicado Gámez Fuentes, esta imagen no es gratuita: «aunque pueda estar asociada al tema de la caza y los furtivos que encontramos en la película, la visión de una caja preñada de símbolos fálicos inaugura la representación del poder, la represión y la violencia que acontece a lo largo de la película con referencia a las relaciones madre-hijo y, por extensión, al Estado» (2003, p. 77). Pero la banda sonora que escuchamos mientras vemos ese primer plano también nos remite a una canción interpretada por Vainica doble, una canción que acaba convirtiéndose en leitmotiv de Milagros en tanto aparece siempre asociada a este personaje y, por tanto, al tema del deseo. En este sentido, el genérico condensa, a través de la superposición de la música y la imagen, dos de los elementos primordiales que se entrecruzan en el filme: represión y pasión, prohibición y deseo, muerte y vida.

Figura 1

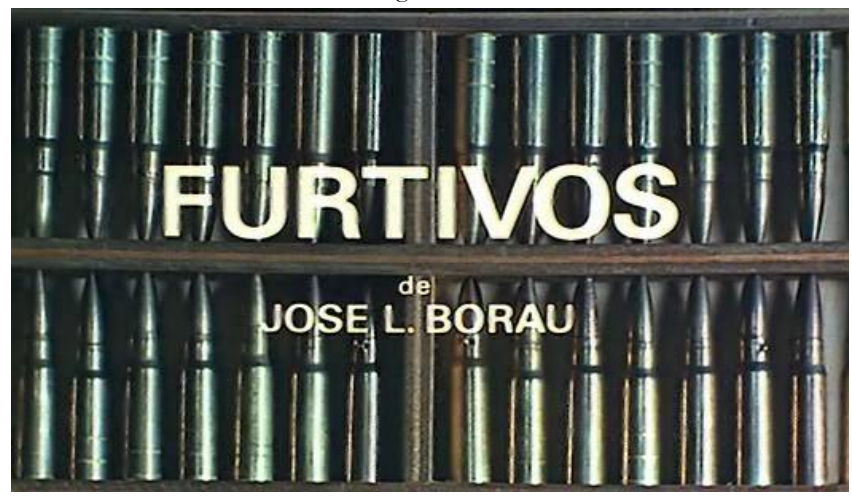

La música se desvanece y del primer plano de las balas pasamos a un acentuado picado de la plaza del mercado, donde un ensordecedor ruido de sirenas de policía irrumpe en escena. Los siguientes planos nos muestran la invasión de las fuerzas de seguridad en el mercado, que está siendo desalojado, para buscar al «Cuqui», un delincuente de poca monta que ha escapado de la Justicia para ver a su novia (Milagros) (Fig. 2).

Figura 2

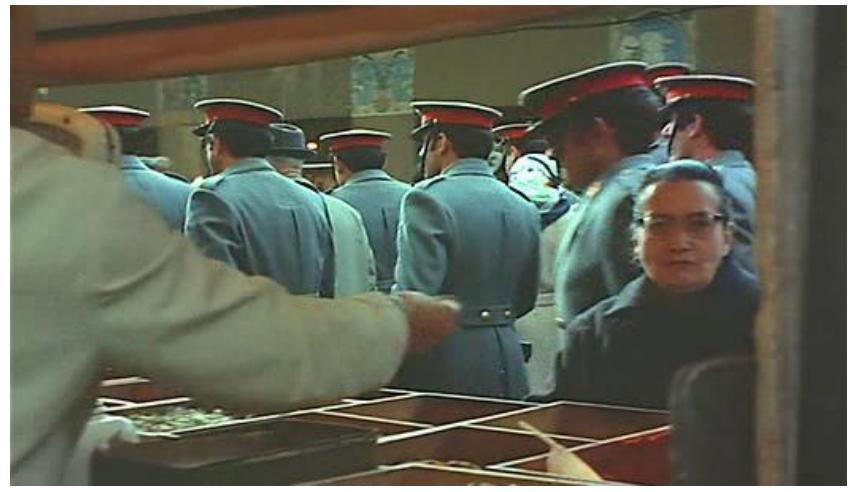


El asalto origina cierta confusión entre los clientes y los vendedores, que son apartados o reducidos a la pasividad por las fuerzas de seguridad, sin miramiento alguno. Un policía choca con una señora que sopesaba en ese momento un conejo, el cual escapa escaleras abajo aprovechando el momento. La entrada de la policía se produce en una serie de planos de conjunto del mercado donde la cámara se coloca como un mero observador más entre la gente. Esta ubicación sugiere una posición alejada del poder represor, representado por las fuerzas de seguridad y una identificación con la mirada del pueblo, encarnado en los compradores y vendedores del mercado (Figura 2).

Tras esta secuencia se produce el primer encuentro entre Ángel y Milagros, el cual supone la apertura de «una poderosa instancia que impulsa el relato hasta su desenlace» (Company, 2012, p. 94). La aparición de Milagros (y la relación que establece con el protagonista a lo largo del filme) resulta crucial para entender la ruptura del sujeto con el cuerpo materno. En tanto Milagros irrumpe en la trayectoria del protagonista y despierta su deseo, se sitúa como el motor narrativo de los acontecimientos posteriores: su presencia en el relato supondrá la ruptura definitiva de la relación incestuosa que el joven mantiene con su madre. Como ha señalado Company (2012, p. 94) su inserción en el relato constata «la irrupción del fantasma femenino como alteridad en la autosuficiente célula incestuosa (más que edípica) en la que se hallan Ángel (Ovidi Monllor) y Martina, su madre (Lola Gaos)».

La escena a la que aludimos sitúa a Ángel en una armería a la que acude con el fin de comprar el alambre y las balas que necesita para ejercer la caza furtiva. Como si de un fantasma se tratara la imagen de Milagros, reflejada en el cristal de la puerta de la tienda, surge de repente. Posando de forma descarada su mirada en Ángel, llama su atención intencionadamente. Pero cuando, instantes después, él la busca con la vista, ella ha desaparecido, así como también el tema musical se desvanece. La seducción, pues, se plantea desde un primer momento como un intercambio de miradas (de las que el espectador es único testigo) en una serie de planos/contraplanos. Poco más tarde, el personaje de Milagros se coloca a sí misma como objeto de deseo de Ángel, tal como podemos observar en el segundo encuentro entre ambos, en el que ella pone en escena su feminidad para seducirlo. De nuevo vemos cómo la cámara sigue todos los movimientos de Ángel, que está siendo observado por Milagros. La chica, que permanece sentada en el banco frontero, tiene ahora una actitud más claramente atrevida e insinuante al descruzar las piernas ante él para atraerle (Figuras 3 y 4).

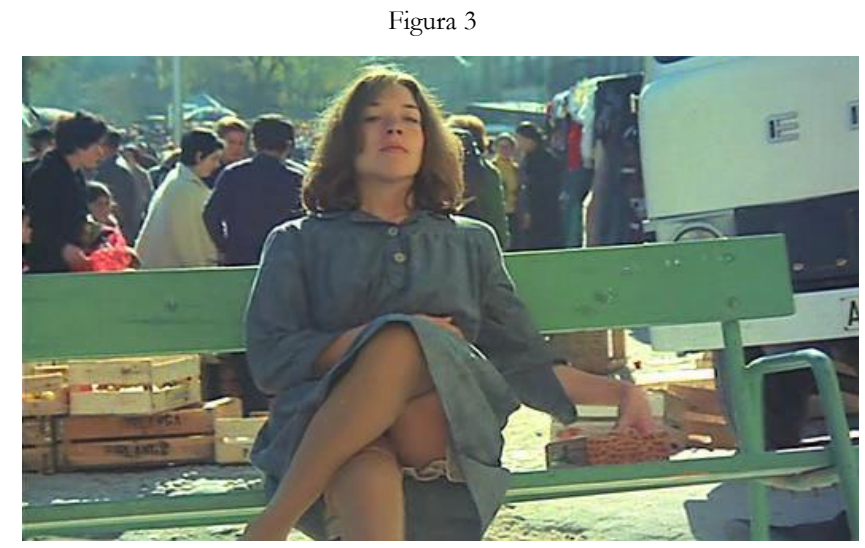




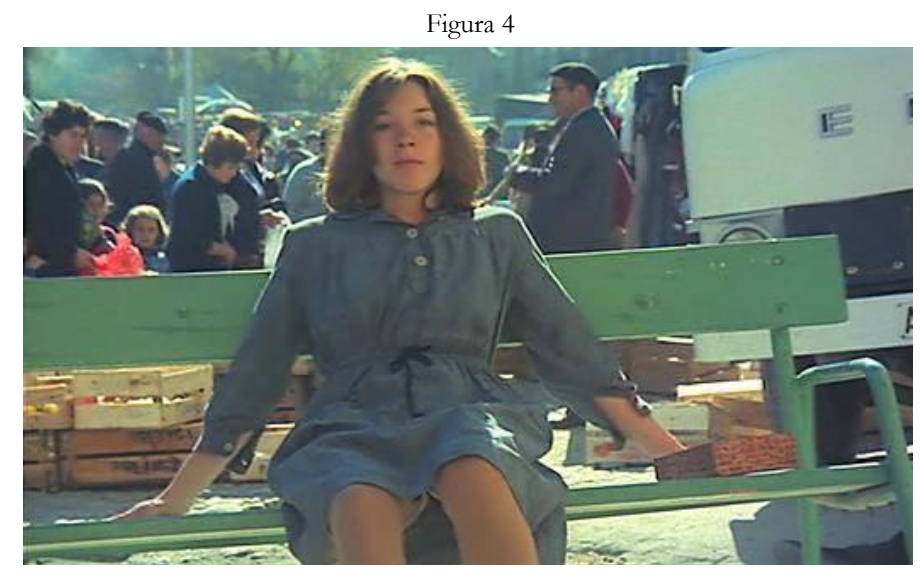

Como bien ha señalado Gámez Fuentes (2003, p. 83) los personajes femeninos en Furtivos actúan como «mediadores en el desarrollo del sujeto masculino desde su crianza a su madurez sexual». Tanto es así que estas primeras escenas sitúan a Milagros como un personaje vinculado al deseo de Ángel, a su viaje hacia la adultez y la inserción en la sociedad, tal como veremos. En este sentido, si él la necesita es para completar su identidad, para instaurarse como sujeto deseante en la narración. Las necesidades de Milagros no tienen que ver tanto con el desarrollo de la identidad, sino con una cuestión puramente material (económica) y mercantilista. En este sentido, tras la primera noche que ambos pasan juntos, Milagros le expresa cómo se trata de un simple intercambio de favores, una relación puramente mercantil en la que ya ninguno debería estar en deuda con el otro: "Yo te he hecho un favor y tú a mi otro. Estamos en paz». Milagros utiliza su feminidad para conseguir beneficios (comida, ropa) que poco a poco se irán incrementando a medida que se integre en la sociedad (casa, cama). En este sentido, lo que al principio parecía simplemente un «intercambio de favores» acaba convirtiéndose, por exigencias sociales, en una reproducción del modelo tradicional de pareja.

Por otra parte, podemos indicar que la indumentaria de Milagros en estas primeras escenas (el uniforme, las medias bastas, la ropa interior «áspera y desagradable» (Borau y Gutiérrez Aragón, 1993, p. 25) contrasta, sin embargo, con lo que ella representa (el deseo, la pasión) en el grueso del filme. En este sentido, estas primeras escenas muestran cómo el cuerpo de la mujer estaba sometido a una fuerte represión sexual. Aunque la joven representa un modelo de feminidad antagónico, contrario al defendido por el discurso de la Sección Femenina, el filme traduce las limitaciones de las mujeres en la España que se describe, tal como ha señalado Gámez Fuentes (2001) (la imposición del matrimonio; la autoridad de las monjas) pues, si bien Milagros se sitúa en un primer momento como agente de la experiencia sexual, a lo largo del filme, su aparente liberación se verá condicionada tanto por los imperativos sociales de la España franquista como por su sumisión ante la actitud de su novio, el «Cuqui», que la abofetea cuando se entera de que se ha casado con Ángel. Por eso mismo, podemos afirmar que la actitud de Milagros se sitúa en la contradicción de rebelarse contra la mujer tradicional que describe el franquismo (discreta, comedida, católica) pero, al mismo tiempo, adecuarse al paradigma patriarcal que regía las relaciones sexuales de los sujetos en esa época.

Si bien todos los personajes en el filme son, en cierta medida, víctimas de la represión, Milagros resulta ser doblemente represaliada por la sociedad patriarcal franquista tanto en materia de género como de clase. Las diferencias entre Martina y Milagros, por tanto, se acentúan también en este aspecto de clase. Mientras que Milagros proviene del circuito de la marginalidad, Martina es una mujer 
pobre, pero que ha sabido colocarse al lado del poder al haber sido el ama de leche del Gobernador. De hecho, esta misma función de ama de leche es emblemática de su precariedad social, pues esta actividad solía desempeñarse por parte de mujeres campesinas que no tenían mayor solvencia económica. En este sentido, su función de madre le ha otorgado una posición privilegiada respecto al poder, tal como vemos en el proceder del Gobernador respecto a la actividad delictiva de Ángel.

La doble moral que rige su actitud aparece satirizada en una escena en que un subordinado suyo alude a la posición privilegiada de Ángel, a lo que el Gobernador, dirigiéndose a los guardas del coto con solemnidad y rectitud, replica: «Vosotros estáis para acabar con el furtivo, sea quien sea»y, acabada de pronunciar la frase, se dirige a la escalera que lleva al desván, levantando la trampilla: un plano nos muestra el arsenal de pieles, trofeos y piezas de cecina que allí se ocultan. Acto seguido, el Gobernador se apresura a cerrar para que nadie de los presentes se percate de la situación. En este sentido, tanto Martina como Ángel se sitúan en una posición ambigua respecto al poder, están dentro y fuera de la legalidad. Con el lema «Pobre pero honrado», el franquismo defendía un discurso moral sobre la pobreza para evitar la «confusión de clases», intentando paralizar las aspiraciones de la clase obrera de unas mejoras económicas y sociales. El filme de Borau se refiere sarcásticamente a esta realidad al mostrar cómo los personajes que aquí representan la clase pobre (Ángel, Martina) deben saltarse las leyes para poder sobrevivir, aludiendo de esta manera a la extrema pobreza que sufría España durante el franquismo.

Más allá de esto se sitúa la cuestión moral, que ambos sortean, asumiendo ante los demás una postura de acatamiento de los valores morales de dicha sociedad, pero, al mismo tiempo, subvirtiéndolos dentro del ámbito privado familiar. Particularmente subrayado en el filme aparece la ambigua relación, sintomática de esta doble moral que rige la vida de Martina, con la Iglesia y sus representantes.

Así, mientras defiende la labor de las monjas con las «chicas perdidas», mostrando su satisfacción ante la fuerte represión que estas monjas ejercen sobre las chicas del reformatorio, evita ponerse a sí misma como objeto de la represión católica en su resistencia a acudir a la Iglesia y confesarse. Esta ambivalencia con respecto al poder aparece retratada no solo en los personajes que representan, de alguna manera, la sociedad rural empobrecida (Martina, Ángel) sino incluso en los que detentan directamente el poder (el Gobernador). De esta manera, Borau establece una crítica al régimen franquista a partir del tropo de la furtividad, aludiendo a la decadencia y corrupción social que el Estado totalitario genera.

\subsection{LO MATERNO EN LOS MÁRGENES}

Martina aparece retratada como un personaje inquietante y siniestro en tanto que conjuga lo maternal (la idea de la mujer estrechamente vinculada con la naturaleza) con el Estado totalitario. Martina impone su autoridad y reproduce el poder a nivel micro -en el seno familiar- a través de mecanismos característicos de la sociedad disciplinaria, como el encierro (del hijo en la casa, en el seno maternal) y el control (del cuerpo). Es característico del Estado policial franquista, tal como ha señalado Álvarez Fernández (2007), la obsesión con la supervisión/sujeción, el orden, la vigilancia, el encierro. Precisamente este tema del encierro (aislamiento/represión) aparece subrayado visualmente en las primeras secuencias del filme a través de distintos planos en los que la cámara se sitúa detrás de los barrotes que cierran diferentes espacios (el mercado y la cancela del edificio del Gobierno Civil) para sugerir la reclusión a la que se encuentran sometidos los personajes. Al mismo tiempo, los acentuados planos en picado en las dos primeras escenas (el del mercado y el del bosque) subrayan simbólicamente el control al que estaba sometida la sociedad española bajo el Régimen franquista. Es precisamente 
esa mirada controladora de arriba abajo, desde el Estado hacia la población la que, desde nuestro punto de vista, comparten esos dos espacios (el mercado/el bosque) en su presentación al espectador. Yendo más lejos, podríamos decir que la estructura paralela de los dos planos establece un símil entre la mirada del Estado y la de la madre. En ambos planos se erige una mirada omnisciente que controla la escena desde arriba. En el primero de los casos el narrador omnisciente no aparece identificado con ningún personaje concreto, podemos deducir que se trata, por tanto, de una metáfora del Estado o de la estructura político-social que reinaba durante el franquismo. En el segundo, quien controla la escena con la mirada es Martina, que está esperando la llegada de su hijo en el autobús (Figuras 5, 6 y 7)5.

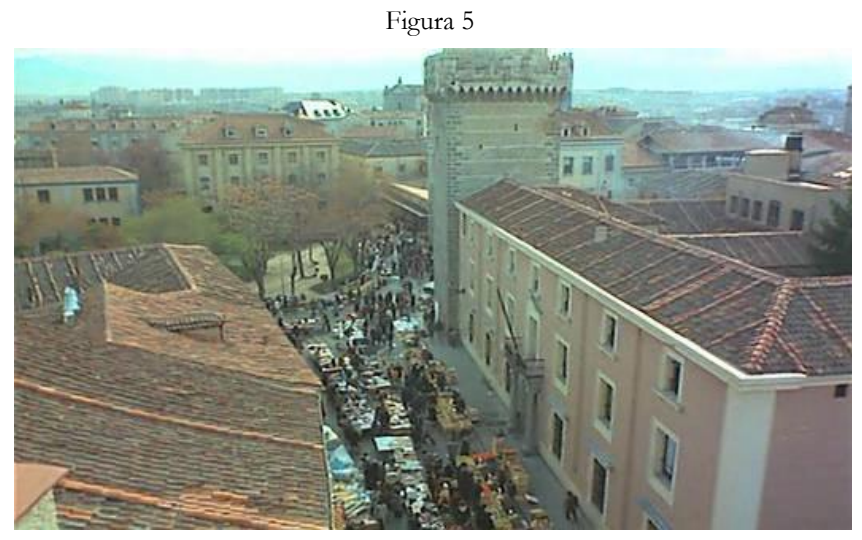

Figura 6

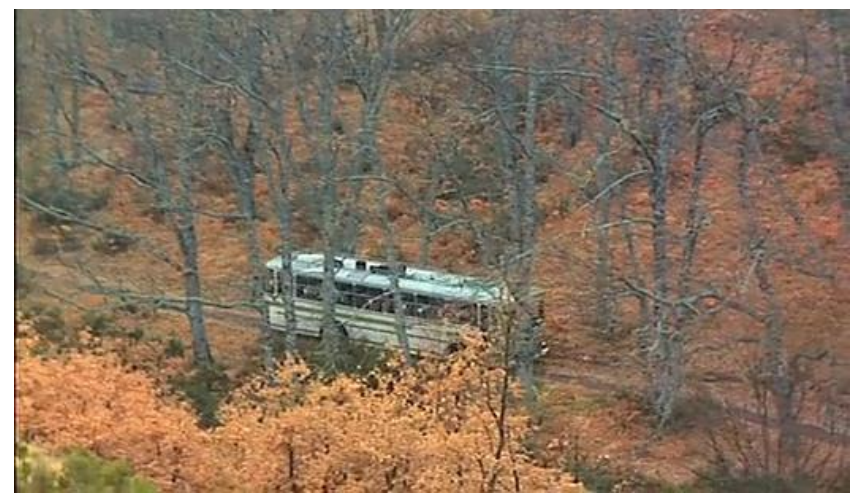

\footnotetext{
${ }^{5}$ No podría haber sido más adecuada la presentación de la madre en ese espacio pues, como bien ha observado Company
} (2012, p. 97), Martina es «una prolongación del paisaje que la rodea, asimilable a la rama sarmentosa de un árbol».

(C) Ediciones Universidad de Salamanca / CC BY - NC ND Fonseca, Journal of Communication, n. 17, 2018, pp. 173-191 


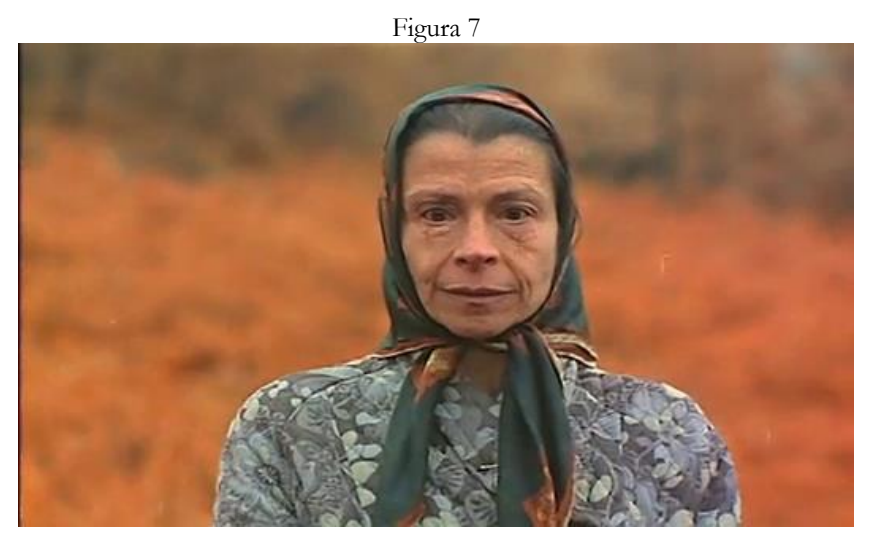

Desde el primer momento la imagen de Martina, con su pañuelo en la cabeza y tapada de arriba a abajo, parece evocar una cierta feminidad rural que cumple las premisas de recato y austeridad impuestas por el discurso franquista. Sin embargo, su actitud agresiva y malhablada poco tiene que ver con la feminidad descrita en los textos falangistas ${ }^{6}$. Bien al contrario, Martina no es el retrato de esa madre frágil, sumisa y sacrificada del franquismo, sino más bien una hipérbole de esa otra faceta materna que tiene que ver con el control y el poder en el seno familiar. Acerca de su marido, como muchas otras mujeres durante la dictadura, no sabemos nada. Ella crió a su hijo y fue ama de leche del Gobernador, perpetuando, en cierta medida, el rol de la madre franquista unificadora de las dos Españas (Gámez Fuentes, 2004).

El primer encuentro entre Martina y Milagros presagia la tragedia. En esta escena, Martina encuentra una loba atrapada en una de las trampas que ha puesto su hijo en el bosque para ejercer la caza furtiva. La misma loba a la que escenas más tarde matará y que sustituirá la violenta escena de la muerte de Milagros, supone un trasunto simbólico no solo de la suerte de la joven que, atrapada entre el reformatorio y el matrimonio con Ángel, muere a manos de Martina de forma similar -sugiere el filme- a la muerte de la loba, sino también de esa madre que, habiendo amamantado a sus hijos (Ángel y el gobernador) se encuentra en decadencia puesto que su cometido en la vida (criar, cuidar) debe ser abandonado para el desarrollo «normal» del hijo. En este sentido, no puede ser más ilustrativo el cartel que Iván Zulueta dibujó para el filme. En él vemos la terrible figura de Martina que aparece despojada de atributos humanos (carece de ojos y nariz), para asimilarse a una gran ave (un buitre) que controla a todos desde arriba, no solo al hijo, al que sujeta fuertemente con sus garras, sino también a Milagros, y, por debajo, al gobernador y al pueblo (Figura 8).

\footnotetext{
6 Tal como ha señalado Zecchi (2002), en los textos de la Sección Femenina se esboza claramente un modelo de feminidad cuyas características las constituyen el hecho de ser católica, devota, angelical, doméstica y discreta.
}

C Ediciones Universidad de Salamanca / CC BY - NC ND Fonseca, Journal of Communication, n. 17, 2018, pp. 173-191 


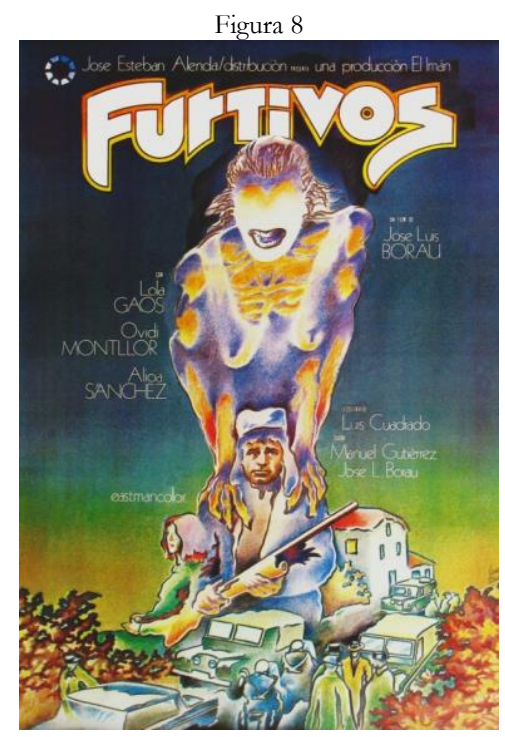

En la construcción del personaje de Martina podemos vislumbrar la idea del monstruo femenino que resulta de la fusión de la mujer y la bestia, condensando simultáneamente humanidad y bestialidad 7 , protección y destrucción, amor y muerte. La animalización de Martina no parece, desde nuestro punto de vista, casual en tanto que tiene paralelismos con la idea de la mujer como naturaleza, esto es, con la identificación de la feminidad con la naturaleza y, por tanto, con la maternidad. Como ha señalado Pedraza (1991), la relación entre mujer y naturaleza, desde la mitología clásica hasta el cine fantástico, ha dado lugar en la cultura occidental a numerosas representaciones de la mujer como monstruo. En Furtivos, la madre resulta siniestra no solo por su animalización en el filme, sino también por el poder que detenta. En este sentido, si podemos afirmar que Martina es un trasunto siniestro de la madre en el imaginario franquista, es porque el propio discurso franquista es el que, desde su visión de mundo conservadora, no solo mantiene a la mujer en la naturaleza (ella es, ante todo, biología), sino que la coloca por eso mismo en una situación «privilegiada» respecto al hombre en la relación con los hijos, le otorga un poder sobre ellos que nadie más puede detentar, ella es la encargada de amamantar, criar, cuidar, limpiar y vigilar a sus vástagos y la conjunción de ambos elementos (naturaleza y poder) es lo que hace de Martina un personaje siniestro, peligroso, ella debe ser aniquilada porque ha llegado a tener demasiado poder sobre su hijo. La monstruosidad de Martina, por tanto, viene dada por su extrema asunción del poder fálico sobre Ángel, por su resistencia a abandonar el poder y sacrificarse por el hijo. Más aún, el exceso de poder en la madre resulta negativo pues acaba construyendo furtivos (Ángel) o fascistas (el Gobernador).

A pesar del tenso encuentro entre Martina y Milagros y el mal recibimiento, esta decide quedarse. Martina sirve leche a Milagros y a su hijo, pero en este caso, el alimento con que amamantó a su hijo y al gobernador, es rechazado por Milagros, que vomita tras escuchar las palabras pronunciadas por Ángel: «Milagros es muy buena. Además sabe coser» (cualidad indispensable en el ideal femenino franquista). Martina enseguida se percata de la procedencia de Milagros y responde a su hijo con un bofetón diciéndole «Yo no quiero saber nada». A partir de aquí todo el relato va construyendo in

\footnotetext{
${ }^{7}$ En otro contexto, la fusión entre animalidad y humanidad ha sido asociada con el concepto de lo siniestro por González Requena (1996).
}

(C) Ediciones Universidad de Salamanca / CC BY - NC ND Fonseca, Journal of Communication, n. 17, 2018, pp. 173-191 
crescendo la separación dolorosa y violenta entre madre e hijo. Esto supone la asunción de una identidad separada de la madre. El miedo y el horror que nos produce esta madre de Furtivos tiene mucho que ver con el miedo a los propios límites corporales confundidos con los de la madre. Paralelamente, el filme de Borau parece hablar de la íntima relación entre Estado y cuerpo, esto es, del control de los cuerpos que, desde las instituciones franquistas, se ejercía sobre el resto de la sociedad. En la promoción de la familia nacional, el control ejercido por el franquismo se dirigía explícitamente a la educación, comportamiento y sexualidad de los sujetos. La identidad de la mujer estaba basada en su función social como madre. Sin embargo, el filme de Borau va más allá al plantear la maternidad entendida no solo como una fuente de identidad para Martina, sino también como una fuente de poder y de placer. Por eso mismo, Martina impide a Ángel el acceso a lo simbólico, a lo social, aferrándose y perpetuando el complejo de Edipo. Ella es, por una parte, la imagen que propone Freud de una madre que amamanta, seduce y estimula la libido infantil para luego reprimirla violentamente con prohibiciones y con la amenaza de castración. Las prohibiciones, sin embargo, en este caso, están referidas al deseo sexual fuera de la relación madre-hijo y, por tanto, se sitúan fuera de la ley del padre. Como propone el título, ambos personajes son furtivos de dicha ley: Ángel puede considerarse furtivo de la ley que le insta a separarse de su objeto originario (la madre).

\subsection{LA RUPTURA CON EL CUERPO MATERNO}

El proceso de salida (acceso a lo simbólico, inclusión en lo social, en la norma) se irá trazando paulatinamente en la relación con Milagros, que lo aleja de la madre para culminar en su nombramiento como guardia forestal. El definitivo reemplazo de la madre por Milagros se produce en una violenta escena, lucha entre madre e hijo, en la que Ángel expulsa a Martina de la habitación, que se resiste con todas sus fuerzas a abandonar la cama. Tras expulsar a la madre, Ángel hace entrar a Milagros, diciéndole «Esta es tu casa y esta tu cama». Aquí se inicia, en toda su crudeza, la separación madre e hijo, que culminará al final del filme con el matricidio. En la siguiente escena, Martina, desesperada y completamente frustrada, sale de la casa y mata a golpes a la loba. Este gesto no solo es un anticipo de la muerte de Milagros a manos de Martina, sino que la escena reemplaza, por así decirlo, la de la muerte de la joven, que ocurre fuera de campo. En este sentido, el filme perpetúa la idea de una íntima asociación entre la madre y la nación, como hemos señalado. Sin embargo, Martina es también furtiva en su afán de fomentar el estancamiento del hijo dentro del complejo. Si bien la prohibición del incesto conlleva el acceso del sujeto al mundo simbólico (González Requena, 1997), en el filme que nos compete la madre se resiste una y otra vez a separarse del hijo. En este sentido, Martina deviene monstruosa en su resistencia a abandonar el lugar en el que la propia sociedad franquista la ha colocado como mujer. Al ejercer su papel de madre, al resistirse a renunciar al ejercicio del poder en la casa, sin embargo, ella misma está subvirtiendo por exceso el ideal que el franquismo propugnaba. Martina resulta una furtiva de una ley social que primero le exige un ejercicio de poder y control sobre su hijo para luego pedirle que abandone el «producto» que siente irremediablemente suyo. $\mathrm{Al}$ mismo tiempo, el desplazamiento o reemplazo de la madre por Milagros no es aceptado, debe ser aniquilado por lo que ella representa (la ciudad, lo desconocido, la modernidad, el cambio, la separación del hijo...) y sustituido por una castración hacia el hijo que le haga volver a la madre.

La estancia de Milagros en la casa no se alarga demasiado, pues la policía acaba averiguando que se ha escapado del reformatorio. Para impedir que se la lleven, Ángel se casa con ella, poniendo de relieve, de esta forma, la importancia del matrimonio como institución que avala socialmente a la mujer. De esta manera se insiste en las pocas posibilidades que tenía una mujer en la sociedad franquista, como le dice el Gobernador a Ángel: «De Las Divinas una mujer o sale casada o sale monja, así 
que tú verás». En este sentido, los personajes se ven constreñidos y condicionados por una sociedad que no da más opciones. El poder subversivo de Milagros se ve amputado con el corte de pelo que la policía lleva a cabo en señal de castigo. El corte de pelo, como símbolo de castración y pérdida de poder, cuyo origen bíblico encontramos en Sansón y Dalila, es un elemento recurrente en el cine español de la época ${ }^{8}$ que, además, hace referencia a una realidad: el corte de pelo a las mujeres y, por tanto, la pérdida de su belleza femenina y la vergüenza de masculinización, era un castigo común que se aplicaba durante el franquismo ante la conducta indecorosa.

Para escapar de las monjas del reformatorio, Milagros acaba asumiendo su papel de casada y renuncia a escapar con su novio en tanto que ve la posibilidad de poder ejercer también su poder/dominio en la casa. En la relación entre Ángel y Milagros, por tanto, podemos observar que el violento reemplazo de la madre por Milagros se efectúa a partir de un modelo de feminidad activa, agente, que le permite rebelarse contra su madre y adquirir independencia respecto de ella. En este sentido, el infantilismo de Ángel se ve cada vez más matizado siendo abandonado poco a poco en su acceso a la vida adulta. La relación con Milagros le ha permitido la experiencia del reemplazo, el sepultamiento del complejo edípico y el abandono de su furtividad, al mismo tiempo que ha inaugurado la noción de fantasía o fantasma, que desde un principio está presente en el personaje de la chica. Por tanto, la fotografía que Ángel guarda celosamente y que determina el cierre del relato nos remite a su primera aparición (imagen, ¿fantasma?, reflejada en el cristal) como pura fantasía que el sujeto hace suya una vez perdida. Por eso mismo, el plano que cierra el relato no es la imagen -fantasmática- de la esposa amada, sino su aspecto infantil e inocente, que es la imagen que él realmente persigue.

La muerte de Milagros se nos anuncia en una escena que recuerda aquella en que las dos mujeres se encuentran por primera vez. En esta ocasión, la posición de superioridad-inferioridad que asumían los dos personajes ha desaparecido, puesto que ambas se encuentran al mismo nivel, aunque la cámara adopta la postura de Martina y nos muestra a Milagros de espaldas a ella, ajena a la mirada amenazante de la mujer. Escenas más tarde, Milagros se afirma como la señora de la casa, confirmándole a Martina su intención de quedarse: «Así es que te quedas, ayer te ibas y hoy te quedas», le dice Martina, a lo que Milagros responde: «Sí, porque soy la mujer de Ángel y esta es mi casa». El espectador no es testigo de la muerte de Milagros, pero la presiente cuando Martina anuncia a Ángel que se ha ido con su novio el Cuqui. Ángel, desesperado, sale a buscarla al bosque en medio de una terrible tormenta, pero no la encuentra. Cuando vuelve a casa, madre e hijo aparecen solos de nuevo en la habitación. Ante tal circunstancia se pone de relieve la satisfacción de Martina por haber recuperado de nuevo el control sobre su hijo. En esta secuencia se produce, por primera vez ante el espectador, la escena de la seducción. Martina se desviste hasta quedarse en ropa de cama y, seguidamente, va desvistiendo a su hijo, regañándole cariñosamente por su travesura, como si de un niño se tratase, secándole el cuerpo y limpiándole con una toalla: «Menos mal que estoy yo aquí, que sería de ti, pobrecito... Cómo te has mojado, pobrecito. Yo te secaré con cuidado... Cariño mío... Tienes los pies helados... Si estamos mejor así, los dos solos, como siempre». Ángel permanece pasivo durante toda la escena, dejándose llevar por los cuidados maternos, hasta que ella se refiere a sus genitales, secándolos y riéndose: «Uy, uy, uy... si se te ve el pajarito», a lo que él responde, levantándose y empujándola: «iNo quiero, déjeme en paz, zorra!» (Figuras 9 y 10).

\footnotetext{
${ }^{8}$ El motivo cinematográfico del afeitado de cabello a mujeres aparece en otros filmes en los que, de diversa manera, aparece el tema del auge del fascismo en Europa, tales como For Whom the Bell Tolls (Sam Wood, 1943), basado en la novela de Ernest Hemingway o Hiroshima, mon amour (Alain Resnais, 1959). Ambas películas tienen que ver específicamente con el tema del fascismo. Por otra parte, específicamente en lo que se refiere a cine español tardofranquista, este tema, con diversos matices, lo podemos encontrar asimismo en películas que apuntan específicamente a la España franquista como Ana y los lobos (Carlos Saura, 1972) o La prima Angélica (Carlos Saura, 1973).
}

(C) Ediciones Universidad de Salamanca / CC BY - NC ND Fonseca, Journal of Communication, n. 17, 2018, pp. 173-191 

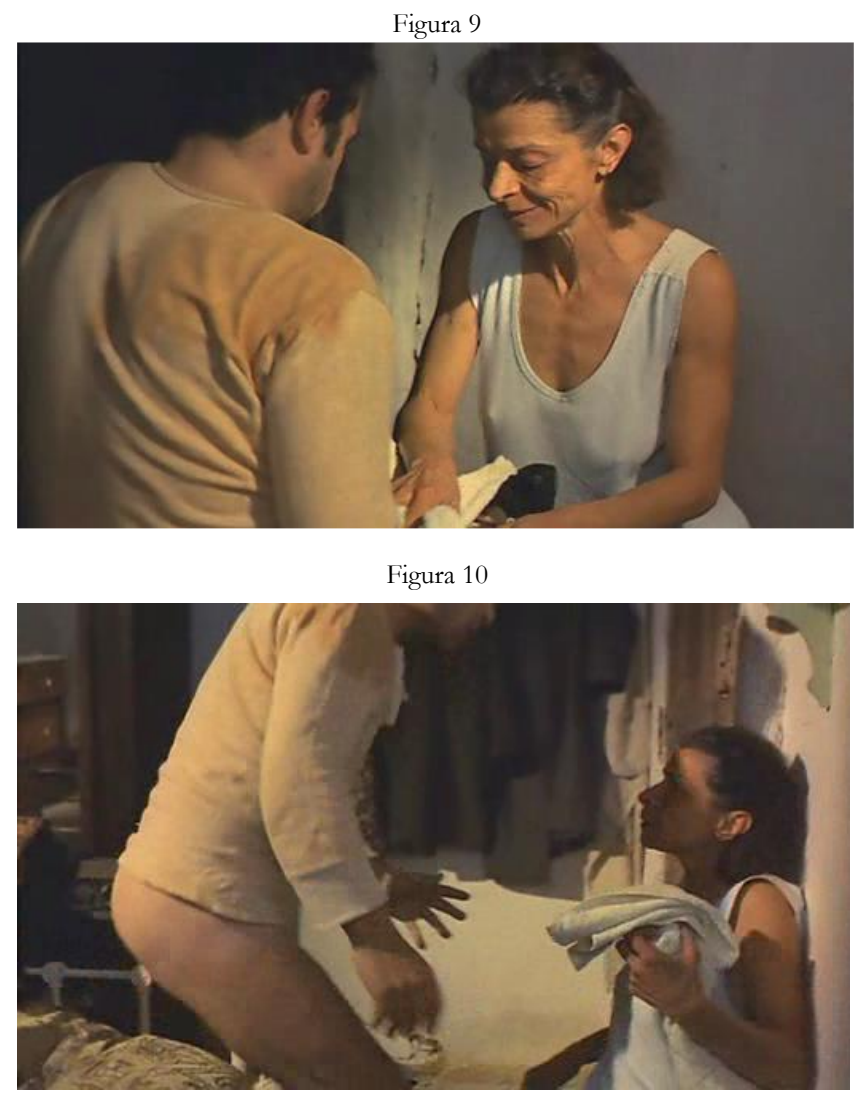

La ruptura con el cuerpo materno, que se había iniciado con el deseo hacia otro objeto (Milagros), hace evidente en esta escena que ya no hay marcha atrás. En este sentido, al repetirse la escena de la seducción infantil, pero más tarde, en un adulto, adquiere connotaciones sexuales (en el caso del filme de Borau, la relación incestuosa madre-hijo). En este caso, el rechazo de Ángel, su deseo por escapar de la madre se traduce en una violencia desmedida que culmina con su ejecución. Tras su matrimonio, se produce un segundo paso para el acceso de Ángel a lo simbólico, a la sociedad, pero es hacia el final, coincidiendo con la pérdida de Milagros, cuando el sujeto rápidamente consigue su acceso a lo social, es decir, escapa definitivamente del deseo de la madre. Por eso es en este preciso instante, y no antes, cuando Ángel consigue el trabajo de Guardia forestal y deja de ejercer la caza furtiva. A partir de aquí y, tras descubrir la irreversibilidad de la pérdida, ejerce la ley del padre de forma radical, obligando a confesar a su madre y castigándola con la muerte. El conflicto de Edipo en el varón, siguiendo la descripción de Freud, se fundamenta en la fantasía de la muerte del padre y la posesión de la madre resolviéndose en la final asunción de la ley paterna bajo la amenaza de castración. En este caso, literalmente el padre está ausente de la escena y la madre es quien se presenta como castradora, pero en un sentido subversivo de la ley paterna al obstaculizar el deseo del hijo por superar el complejo edípico y acceder a lo simbólico. Por ello, el matricidio en el filme supone la asunción de la ley paterna por parte de Ángel.

Esta penúltima secuencia del filme, al igual que la de la loba y la muerte de Milagros, ha sido anunciada anteriormente en la ejecución del ciervo que el Gobernador deseaba matar. De la misma 
forma muere Martina, aunque esta vez de nuevo, fuera de campo. El filme termina con un plano de la fotografía de Milagros de niña. Lo que al final perdura para el sujeto es la noción de fantasma en Milagros, no la esposa real con la que Ángel se casó, sino esa otra dimensión, la imagen infantil e ingenua que en realidad persigue, imagen que se sitúa ya como pura representación del deseo del sujeto. Lo que permanece, por tanto, más allá de toda materialidad, es el deseo de Ángel, esta vez constituido en la falta. En este caso, Milagros -su imagen, su fantasma- queda instalada definitivamente como el puro objeto de deseo, siempre como ausencia, como pura fantasía que aleja el horror real de la situación. Lo que en definitiva perdura es el deseo del sujeto de someterse a la ley del padre, sepultando el complejo que, traumático por definición, lo es en este caso aún más, al haberse hecho efectivo el incesto durante tantos años. En este sepultamiento no solo se ha separado radicalmente de la madre, sino que ha guardado para sí, como objeto de deseo, la fantasía de una Milagros pura, inocente, infantil, una Milagros que deviene el contrapunto de la madre fálica monstruosa. Pero he aquí que deviene la paradoja: la búsqueda de la independencia de la madre (agente de poder) viene avalada ni más ni menos que por la asunción de la ley paterna y, aún más, los poderes que le han dado la legitimidad a Ángel para deshacerse de la madre (la Iglesia, el Estado) no son sino otros nombres del padre o, dicho de otra forma, representantes de las élites que permanecerán después incluso de la muerte del dictador. En definitiva, por tanto, lo que al final asume el filme es la incapacidad del sujeto para escapar al poder, a la ideología, puesto que para deshacerse de una poderosa fuente de poder debe atarse y someterse a otra(s). En este sentido, tal vez augurando lo que constituiría la transición, una asunción y continuación de los poderes e instituciones anteriores, el filme propone una visión escéptica respecto al afán emancipador de la izquierda española.

\section{CONCLUSIÓN}

En este artículo hemos abordado el análisis de la figura materna en Furtivos tomando en consideración el texto fílmico como un síntoma de determinadas problemáticas sociales, históricas, culturales que interpretamos en relación con los procesos históricos de la transición a la democracia. Esta consideración se debe, en buena medida, a la vinculación que ciertas representaciones fílmicas de la transición -en especial aquellas desarrolladas en el marco del denominado «cine simbólico-familiar»- habían llegado a establecer entre la figura materna y la dictadura.

Para realizar el análisis hemos partido de una perspectiva interdisciplinar que nos permitiera atender a la complejidad discursiva de lo materno en el filme, contemplando las convergencias teóricas y metodológicas entre la semiótica fílmica, el psicoanálisis y el feminismo. La bibliografía explorada sobre lo materno en Furtivos (Evans, 1999; Gámez Fuentes, 2003; Russell, 2008) subraya la pertinencia de combinar la teoría psicoanalítica lacaniana con las aportaciones que, desde el feminismo, nos ofrece Kristeva (1989). La presente investigación se sitúa en esta línea, retomando ciertos conceptos referidos en los análisis (como el complejo de Edipo o la noción de castración) que considera cruciales para la interpretación del filme, pero amplía su campo de estudio con la aportación de un análisis específico de la noción freudiana de «lo siniestro» en su relación con la construcción cultural de la maternidad.

Por otra parte, y habida cuenta de la importancia de leer los textos fílmicos en conexión con su contexto socio-histórico, consideramos el filme como un texto fundamental que surge como síntoma cultural de la gestión del pasado dictatorial por parte de la sociedad española. A tenor del análisis realizado se aprecia que, en el caso de Furtivos, las exigencias políticas de exorcización del inmediato pasado franquista se vehiculan a partir de la oposición a una figura femenina que, culturalmente, viene a considerarse la representante simbólica de la dictadura: la madre fálica, deformación grotesca de la ideología doméstica propugnada por el régimen. Aparecen en ella mezclados, por tanto, los discursos 
en torno a la patria, la madre y el Estado dictatorial, tal como ha sugerido, en este sentido, el propio Borau, que ve en el personaje de Martina la representación del «país mismo que quiere a sus hijos por y para sí mismo, que los amamanta y los estruja, los devora» (citado en Gámez Fuentes, 1997, p. 115).

En este caso, la distancia entre la ideología conservadora y la representación fílmica de la misma se hace evidente a partir de la crítica política al estereotipo, que aparece planteado como exceso, como un monstruo en su extrema asunción del poder dentro del marco del hogar. En este sentido, la representación de la figura materna en Furtivos, identificada con el franquismo y con la Ley, resulta doblemente monstruosa: por una parte, por su extrema asunción del poder en el marco hogareño y, por otra parte, por su resistencia a desprenderse de su objeto de deseo (el hijo), objeto que el mismo discurso normativo había colocado como epicentro de su existencia. Desde nuestro punto de vista, cabe interpretar la estrategia de defensa ante la amenaza de lo materno como una resistencia crítica referida al régimen franquista. Pero esa resistencia también remite a los peligros asociados a la maternidad en la cultura patriarcal, a los recelos y prevenciones ante la posibilidad subversiva de que lo materno se acabe instalando en un lugar ajeno a lo normativo.

\section{BibliografíA}

Álvarez Fernández, J. I. (2007). Memoria y trauma en los testimonios de la represión franquista. Barcelona: Anthropos.

Aranzubia, A. (2012). Tópicos de lo español. Notas sobre la recepción crítica de Furtivos dentro y fuera de España. En R. Cueto (Coord.), Clásicos del cine español. Furtivos de José Luis Borau (pp. 145-157). Valencia: Ediciones de la Filmoteca (IVAC).

Ballesteros, I. (2001). Cine insurgente. Textos filmicos y contextos culturales de la España postfranquista. Madrid: Fundamentos.

Borau, J. L. y Gutiérrez Aragón, M. (1993). Furtivos. Viridiana, 4, 16-126.

Casetti, F. (2000). Teorías del cine. Madrid: Cátedra.

Colaizzi, G. (2006). Género y representación. Madrid: Biblioteca Nueva.

Colaizzi, G. (2007). La pasión del significante. Madrid: Biblioteca Nueva.

Company, J. M. (2012). Crudezas de la carne. En R. Cueto (Coord.), Clásicos del cine español. Furtivos de José Luis Borau (pp. 91-104). Valencia: Ediciones de la Filmoteca (IVAC).

Evans, P. (1999). Furtivos (Borau, 1975): My Mother, My Lover. In P. Evans (Ed.), Spanish Cinema: The Auteurist Tradition (pp. 115-127). Oxford: Oxford University Press.

Freud, S. (1973). Lo siniestro. En Obras Completas, Tomo VII, Madrid, Biblioteca Nueva.

Gámez Fuentes, M. J. (1997). La angustia de tu corazón mujer compénsala con la serenidad de que ayudas a salvar a España: Una aproximación al discurso franquista sobre la feminidad. Lectora: revista de dones i textualitat, 3, 105-116. http://revistes.ub.edu/index.php/lectora/article/view/6449/8217

Gámez Fuentes, M. J. (2001). No todo sobre las madres: cine español y género en los noventa. Archivos de la filmeoteca, 39, 69-85.

Gámez Fuentes, M. J. (2003). Género, representación y medios: una revisión crítica. Asparkía, investigación feminista, 14, 59-70.

Gámez Fuentes, M. J. (2004). Cinematergrafía. La madre en el cine y la literatura de la democracia. Castellón de la Plana: Publicacions de la Universitat Jaume I.

González Requena, J. (1996). Lo grotesco, lo siniestro, la psicosis. En R. de Diego y L. Vázquez (Eds.), De lo grotesco (pp. 155-170). Vitoria: Universidad del País Vasco.

González Requena, J. (1997). Emergencia de lo siniestro. Trama y fondo, 2, 51-75. 
Heath, S. (1981). Questions of Cinema. Bloomington: Indiana University Press.

Heredero, C. F. (1993). La producción crítica frente a Furtivos. Viridiana, 4, 137-153.

Hopewell, J. (1986). Out of the Past: Spanish Cinema After Franco. London: British Filme Institute.

Kinder, M. (1993). Blood Cinema. The Reconstruction of National Identity in Spain. Berkeley: University of California Press.

Kristeva, J. (1989). Poderes de la perversión. Madrid: Siglo Veintiuno Editores.

Martínez de Mingo, L. (1997). José Luis Borau. Madrid: Fundamentos.

Muñoz Álvarez, V. (2011). Cult movies: películas para llevarse al infierno. Madrid: Eutelequia.

Pedraza, P. (1991). La bella, enigma y pesadilla: esfinge, medusa, pantera. Barcelona: Tusquets.

Rodríguez, H. J. (2008). Un extraño entre nosotros: las aventuras y utopías de José Luis Borau. Madrid: Notorius Ediciones.

Sánchez Vidal, A. (1990) Borau. Zaragoza: Caja de Ahorros de la Inmaculada.

Van Liew, M. (2001). Transitional Visibility in Poachers: The Nature of Female Violence in the Cinema of Post-Franco. Quarterly review of filme studies, 18(4), 425-435.

Vegetti-Finzi, S. (1996). El mito de los orígenes. En S. Tubert (Ed.), Figuras de la madre (pp. 121-154). Madrid: Cátedra.

Zecchi, B. (2002). Contradicciones del discurso femenino franquista (El ventanal). En R. Medina y B. Zecchi (Eds.), Sexualidad y escritura (1850-2000) (195-212). Barcelona: Anthropos.

Zurián Hernández, F. y Herrero Jiménez, B. (2014). Los estudios de género y la teoría fílmica feminista como marco teórico y metodológico para la investigación en cultura audiovisual. Área abierta, 14(3), 5-21. doi: http://dx.doi.org/10.5209/rev ARAB.2014.v14.n3.46357 